\title{
Resurrection of Words in "Zemestan"(Winter) Poem of Akhavan Sales
}

\section{Dr. Mohammad Behnamfar}

Associate Professor of Persian Language\& Literature Dept,. University of Birjand, Email: mbehnamfar@birjand.ac.ir

\section{Golnaz Mirsalari*}

Corresponding Author, Master of Persian Language and Literature, University of Birjand

\author{
Dr. Seyed Mehdi Rahimi
}

Assistant Professor, University of Birjand

Doi:10.5901/mjss.2015.v6n4s2p359

\begin{abstract}
Words in everyday language have their dictionary meanings. But as they pass through their ordinary norm, begins resurrection of words. Literature, especially poetry, is associated with deviating from the norm. This feature in the contemporary literature can be analyzed in different ways. Akhavan who is one of the greatest and popular poets has done most resurrection of words in his poems. In this article we have tried to show the resurrection of words in "Zemestan" (winter) which is the name of one of his famous poems. The results of the research which has been done with content analytic method show that the most important aspect of the resurrection of words in "Zemestan" is his tendency to archaism and structures of ancient poetry along with imagery. Omid (Akhavan) has made a construction that is rooted in past times, especially khorasani style. And he has used every day words and phrases to create new compounds and so has caused them to be resurrected. So Akhavan has made a major contribution to the enrichment and development of the Persian language.
\end{abstract}

Keywords: Akhavan Sales, Zemestan(winter), resurrection of words, Deviation from the norm , defamiliarization, contemporary poetry

\section{Introduction}

Belief in the resurrection of words originates from Russian Shklovsky views and Czech portraitists particularly Mokarovsky and Harrahek. Russian portraitists recognized two language processes from each other and named these two processes automatization and outstanding. Ninety-five years have passed since the publication of the thesis entitled "The Resurrection of the words" by Shklovsky, but still rereading their theory with respect to the evolution of twentiethcentury literary theory of formalism to structuralism and structuralism to post-structuralism is essential. Russian structuralists say when every word goes away from his vocabulary field and is used in a new form and in a virtual concept, resurrection of words have been begun. At the present time, the resurrection of words echoes widely in Akhavan works. He selects a word based on aesthetic and semantic approaches and his beauty switching abilities not merely based on principals and certain rules. Apparent form and music of the words and letters and modulation way of them and their real and virtual meanings and also order of syllables (rhythmic) and phonetics of words (rhyme) have been considered by the poet. Akhavan utilizes his mental power integrity for protecting Persian language and reviving timeworn words and creating new combinations. The most important characteristic of Akhavan's poem is his language that talks with today language while adhering to the traditions. Akhavan has applied a type of historical language instead of another type of live language. It means he has given resurrection to historical and old Iranian words. Akhavan could make his own new thoughts in form of poet by finding independent language. Horras, the famous Roman poet and verbalist, says: "the language is like woods trees that is a collection of old and new leaves" (Shahindezhi, 1999: 134). He has could use words from today spoken language such as damet garm, tipa khordeh, najoor besides communicative and old words and make consistent these types of words and communications skillfully. Akhavan firstly said classic poems imitating Khorasanian poets' style. His first collection entitled Arghanoon has been written in this way. But his poetry path was changed after familiarizing with Nima. He started poetry with new style in winter notebook and in this way he went to where he could found a new style in Nima poetry. Akhavan is both modernist poet and innovator. Many of poets such as Shiraz Khajeh, 
Khayyam, Molana, and Sanayee have started innovations in their era. But their innovation, quantity, and quality are different. Therefore, innovation is not against the tradition but it is besides the tradition that has been a new concept in its era. He says in introduction of Winter collection: ((I have tried to go from Khorasan to Mazandaran through a shortcut, from yesterday Khorasan to today Mazandaran. I try to link nerves and healthy and correct vessels of a clean and common language that often is a live fabric of a stable bone of the past to today blood, beat, and feeling (Akhavan Sales, 2011: 13). Akhavan turned to innovation through old traditions. This Akhavan's innovation was not a return to the past but his intention was resurrection of Iranian tradition. M. Omid started familiarizing with Nima poetry that is clear at first poem of this collection (Winter) of course which is one of his raw experiences:

\author{
I never forget, never \\ That night, the world was world of grace and peace \\ I was and Tooran and the world had the pleasure \\ And it blinked eagerly and its face was toward us \\ The moon through the scrappy clouds (Akhavan Sales, 2011: 21)
}

The geometrical shae of this poem is as same as Nima fiction shape. However, five hemistiches that second and fourth hemistiches have a same rhyme but third and fifth hemistiches are free. The content is descriptive and romantic. Gradually, the poet learns four pieces and enters to Nima poetry field by saying Satarvan poems. Satarvan poems are the first Nima poetry of Akhavan. To Winter poet, his language does not has necessary stability but in Winter poem that we read it with a torrent of words, a impact music, and its up righting end, we see some attempts for achieving a particular procedure in some places. Sometimes a purpose is delightful in the poem that causes hopelessness. Gradually and with a caution we see an attitude to broken rhythmic which its perfection is observed in Winter poems. Saying Winter poems was simultaneous with the failure of August 18, 1953 (Mordad 28th, 1332). Undoubtedly, this poem was the most successful attempt of this poet until anuary 1956 (Dey 1334). Akhavan language in this collection is clean and refined. He utilizes a wide range of words and is never affected by a impasse (Shahindezhi, 1999: 155).

\title{
2. Resurrection of Words in Akhavan's Poetry
}

Some papers have been written according to investigations conducted about norm escaping and outstanding in Akhavan's poems. But it seems applicability of the word in Akhavan's poems needs more investigations. We try to investigate the various types of word resurrection in Akhavan's poem regarding Dr. Shafiee Kadkani 's ideas about resurrection of words to find out in what fields, most resurrection has been performed and what useful effects it can have on our literary society. For this purpose, only collection Winter poem has been investigated as a sample. Before investigating the various types of word resurrection, it is necessary to state Dr. Shafiee Kadkani 's idea about resurrection of words. He says: ((words are used in daily language in such a way that they are addictions and dead and do not attract our attention but in a poem these dead are revived just through a brief displacement of words and a word placing in center of a hemistich also results in life of the other words. Dr. Shafiee Kadkani classifies the resurrection of words in two categories:

a) Musical group including rhythmic, rhyme, row, and audio synchronizations

b) Linguistic group including metaphor, figurative language, sensory, metonymy, briefness, omission, archaism, language combinations, defamiliarization, and saying paradox.

From view point of Dr. Shafiee Kadkani, if we say "it's raining", it is a usual application of the language. But if we say "I went to the desert, the love has been rained", the love word has been resurrected because this is an application against the general and usual application of the language (Shafiee Kadkani, 2010: 5-38). Akhavan is one of slight poets that vocabulary field of his speech is to extent of Persian literature history from third century to the contemporary age. And this extent of his vocabularies has been obtained under the effect of research and investigation in works of old poets especially Khorasanian style poets. The art of Akhavan is in this that he selects the words according to initial materials of Persian language and enters them in his own poem as though he causes the resurrection of these vocabularies and has revived them. Selection of these vocabularies has been done in an artistic way that not only does not cause boredom and disgust in the audience but also excites them. Forough Farrokhzad says about the art of Akhavan in applying words: ((he particularly pays attention to purity and originality of words and perceives real concept of words and places each of them in such a way that we cannot replace them with any word else (Nouri Ala, 1969: 204). Akhavan pays attention to all semantic, musical, and emotional aspects of the words and makes them consistent with the other words as though these words have been revived. Akhavan applies various types of ancient and old words, Persian language contemporary 
words, slang words, and local dialects and languages with each other and makes intimacy and affection among them. Thus, we can consider Akhavan one of a few Persian language poets. Now, we investigate various types of resurrection words in Akhavan's Winter poem:

\title{
3. Word Resurrection
}

The purpose of word resurrection in Akhavan's poem is innovative words that are a mental figment of Akhavan. Akhavan never has a lack of words in his own poems and invents new words against rules of word construction wherever it is necessary that components and elementary materials of all of them are available in Persian language. This type of pattern can help development and richness of Persian language and even can also be a good pattern to construct a word in the other sciences. Russian structuralists has named this type of word construction, word norm escaping. Kourosh Safavi says about word norm escaping: ((this type of norm escaping is one of methods that a poet highlights his own language through it. Thus he/she creates new words and applies them based on escaping from normative word construction)) (Safavi, 1994: 49). The order of word construction in Akhavan's poem is as follows:

\subsection{Construction of combined words}

\subsubsection{Noun + verb stem}

It is hidden into sturdy coffin of the darkness, not into death-line (Marg Andood) (Winter, 2010:109)

Or he says in the other place:

Like the world rounding (Donya gard) eagle

Its hunt in culmination of ether

Seeks and does not seek (Winter, 2010: 49)

\subsubsection{Adjective + verb stem}

\author{
Distressing (parishan gard) poet \\ Takes home way \\ With a rapider step (Winter, 2010: 50)
}

Mohaymeni says: ((poetry language does not comply from available order in its own different aspects and creates a new world, namely poetic world)) (Mohaymeni, 2000: 45). Akhavan has created this world in his own mind. He has constructed a place for a mythical creature, demon, in his own poetic world by adding suffix "lakh". Pay attention to the following hemistiches:

\author{
And that your clean spring from this plain full of demon (divlakh) \\ Was so distant and nobody knows \\ that mountains had generosity or it was Toor mountain (Winter, 2010: 90).
}

\section{Resurrection of Ancient Words}

Akhavan's interest to Iranian cultural heritage and his study and investigation in works and poets of the ancients result in development of his word field. One of important indices of Akhavan's poetic language is that he could revive the culture of Iranian original words and give them resurrection. He selects words among old synonym words and places them besides today words as though these words have re-risen and have born again. In selection of ancient words, he chooses words that can induce his expected meaning well. Akhavan creates a new poetic language for himself based on old language tradition and combining ancient words with today ones that are production of his unique mentality and individuality. Akhavan's poetic language is the field of innovation and reviving words. Every artist presents his/her own selections and secessions resulted from facing with outside world and reflection of his/her inside worlds in form of a new and innovative design in artistic raw material that is a portray of his/her art. Akhavan's portray of art is the resurrection of words, the words that are very structured, targeted, complicated and systematic that are originated from today language and even spoken language and dialectic ones. Akhavan is a linking ring between old words and today language that Bahar quotes about it: ((it has found cripple tone and closed, oppressed, and cagily forms after Mongol invasion)) (Bahar, 1991: 198). 
Akhavan refers to this case in one of his interviews and says: ((I bring the cultured language before Mongol decline into the poet essence and these new approaches and this language became full of perfect novelty for me and placed old rhetorical features from view point of simplicity, health, accuracy, and correctness and the power of this force disposal to this sense and today beat and hesitation (Tahbaz, 1968: 16, 17). A service that Akhavan performed for Persian language words and revived them is very valuable, because he has amplified treasure of Persian language words to create friendship between old words and today ones. Abdul-Ali Dastgheib says: ((he greatly hoped to revive old words and was rightfully very strict about Persian literature heritage. His researches in Iranian literature and recognizing its delicate species and his commitment for keeping prosodic and Nimaian weight makes him different from the other new poets (Dastgheib, 1994: 31-32).

We can classified the ancient words used by Akhavan in his poems: 1- noun 2- verb and 3-letter

\subsection{Noun}

Ancient and old nouns that Akhavan used them in his poems and revived them are classified into two groups: 1-dead words 2-low usage words.

\subsubsection{Resurrection of dead words}

The purpose of resurrection of dead words is to use words that are not applicable in contemporary Persian language but Akhavan revived them and entered them into Persian language. The use of ancient words also exists in works of the other poets such as Nima, Shamloo, and Shafiee, but Akhavan selects words so artistic due to his perfect familiarization with rich culture of Persian words and places them beside today words that these forgotten words suddenly change their identity, became alive, grow longer, and construct a live and integrated unit with today words. Igelton says: ((the poem makes implication active and places the words in such situations that present their own extreme performance under pressure of around words and release the richest talent of themselves (Igelton, 2001: 140-142). Indeed, the words show their superior performance in Akhavan's poem. Pay attention to the selection of ancient words in the poem below:

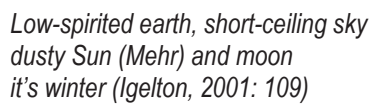

the word Mehr is an ancient word that has been placed besides today words. If Akhavan used today meaning of Mehr, namely sun (Khorshid) instead and said:

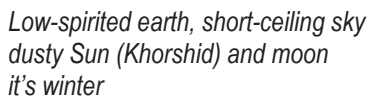

the order, arrangement, and music of the other words were disrupted and the poem missed its own attraction, but the word Mehr has been revived and has caused revival of the other words. Also, pay attention to the resurrection of Ghariv (scream) in the couplet below:

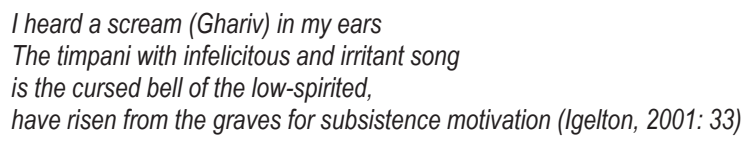

Some of the other ancient words have also been resurrected in this collection: Blour Ajin (p. 109), Dakhmeh (p. 37), Zamharir (p. 178), Safir (p. 64), Sala (p. 64), Zarvash (p. 163), Boghnoudeem (p. 163), Hamgenan (p. 179), Dorj (p. 30), Sarir (p. 30), etc.

\subsubsection{Resurrection of low-usage words}

Some of words are not dead words but do not have any application in our contemporary language. Dr. Shafiee Kadkani says: ((the concept of archaism in our viewpoint is not related to the usage of dead words even selecting older 
pronunciation of a word is a type of archaism, however, the poet can utilize various forms of a word according to his/her musical and mental need that only one of them is applicable for public in usual norm of a live language (Shafiee Kadkani, 1991:25).

Akhavan's familiarization with old texts and his domination on Persian words had caused he necessarily revived these low usage words in his own poem and solved some of word needs. Some of these words are:

Lik (but) (p. 116), Nac (now) (p. 196), Inak (just now) (p. 163), ze ensan ke (from human that) (p. 200), Bedan san (so that) (p. 200), Alak (p. 69), Besan (like) (p. 142), Bedin san (so this) (p. 160) ...

A typical usage of these words in Akhavan's poem:

I prostrated against his/her height but (lik) my heart was beating

I saw him/her that slowly laughed for my unobtrusiveness (same: 29)

The word lik (but) is a low usage one, but correct selection has also caused the resurrection of this word.

Or he says in another place:

$\mathrm{Nac}$ (now) I had a gift for you from love city

To be your confidant in separation-night sorrow (same: 30$)$.

\subsection{Resurrection of ancient verbs}

Akhavan revived the ancient verbs and used them besides today Persian words as though they have resurrected again. In a usual language, a sentence finishes with a verb but in poem language, a sentence starts from the other side of the verb. Akhavan selects these verbs with enormous obsession. One of the reasons of Akhavan's attitude to the selection of ancient verbs is his tendency to mythologies and Iranian epic soul. In importance from aspect of verb archaism, that is enough that the phrases without old structural verbs are less capable to show their own archaistic face, however it is possible to have heavy words and structure (Alipour, 1999: 316).

Some usages of these words in Akhavan's poem:

We have slept (bogh nou de im) in vicinity of the sky's untrue mercy, man

That there is not any memory of them

If there is, it is only in ominous deception of the other clean lives (same: 63). (rise).

Akhavan creates an epic space in his own poem like Khorasanian style poets by selection of the verb baramad

The darkness rose (baramad) from fume straw back of the seas.

Following it, the other darkness rose with a tricky glance, with a hanging tear (same: 53)

One of the significant points in Akhavan's poem is the applying old verbs besides slang words. He applies them besides each other in such a way that both slang words and old ones resurrect together. When Akhavan says in his famous poem of the Winter:

I have come (amadastam) tonight to pay back the loan (vam gozaram)

And to put your debt besides the cup (hesabat ra kenar jam bogzaram) (same: 109)

Vam gozardan (Payin back the loan) and hesab ra kenar jam gozardan (put the debt besides the cup) are slang words that Akhavan has applied them with Neishabour old verbs, amadastam, and has given these words an epic space. Akhavan sometimes takes apart the verb to create resurrection and put the main part of the verb at the beginning of the poem and revives the verb in this way. Furthermore, he gives his own poem a kind of archaistic identity. Pay attention to a sample about that in this collection.

He takes apart the compound verb natvanad deed (cannot see) and to emphasize on the meaning of the deed (see), he used it before helping verb, natvanad (cannot). The other samples of the ancient verbs in this collection:

Nemiyarast goft (p. 29), sar bar keshideh and (p. 33), baramad (p. 53), nahadastand (p. 67), bararad (p. 71), sar bar niarad kard (p. 107), ardha bikht parvizan avikht (p. 38), yazi (p. 108), bogh nou deh iem (p. 163). 


\title{
4.3 Resurrection of words by selecting ancient letters
}

Akhavan has also used ancient Khorasanian style letters to resurrect his own words. As well as emphasis on complement, he has given his own poem an epic space. Akhavan has applied ancient and old letters in following forms in this collection.

\subsubsection{Applying old preposition alone:}

I remember from (ze) that day and time well

Every peace and happiness was with (kandar) you (same: 90).

\subsubsection{Applying two prepositions for a complement}

Akhavan like Khorasanian style poets has applied two prepositions for a complement to emphasize on the complement and its resurrection.

$$
\begin{aligned}
& \text { In to (dar be) pelican beak } \\
& \text { a soft green leaf full of dew (same: 39). }
\end{aligned}
$$

\subsubsection{Applying preposition at beginning and the end of the complement}

\author{
Written on the stone \\ that you don't read a Hadith (same: 154)
}

\section{Resurrection of Slang and Colloquial Words}

Yadollah Royaee, a contemporary poet, says: ((one who is busy on the words, a preoccupation before words, has an eternal preoccupation and the word is our eternal guest. Each of us, poets, has a language in the language)) (Royaee, 2002: 25). Akhavan's language is similar. It means slang and colloquial words accompanying with contemporary Persian words and ancient ones also resurrect in his poem. Akhavan's language is not a language in the streets and markets, but there are street and market colloquial words in his poems. Akhavan has applied slang and colloquial words in following forms in rhis collection: 1-slang words 2-slang sounds and 3-interjection noun

\subsection{Resurrection of slang words}

One of the Akhavan's innovations is the selection of colloquial words in the poem. Akhavan has stated this issue in this form. ( $($ have taken interests from slang language of the time. I have placed the words that are used in the slang language besides old ones but the incorporation type of them is without any intention)) (Kakhi, 1992: 465-466). Some colloquial words in Akhavan's poem are as follows:

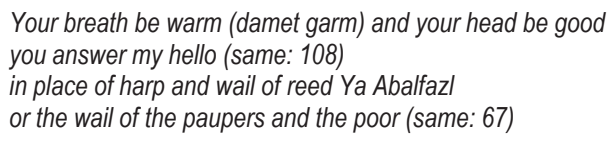

\subsection{Resurrection of words using slang sounds}

Akhavan applies his inducing ability of language and whole of his artistic creation to communicate with the readers by reviving words. He sometimes selects a sound came from public slang language. He has known this ability and uses it well. Some samples of sounds in this collection are: ve, vay, ey, hoom...

Wow (vay) do kind neighbors wake up to help?

This tyrant fire burns my foundation

I scream hey! Hey! (same: 86) 


\subsection{Resurrection of interjection noun}

In Akhavan's poem, language phonemes also play a role for inducing meaning, space, emotions, and feelings. Substantially, mysterious and artistic attitude of Akhavan such as world's mysterious one is in inducing property of their points, latency and veils. Phonemes and points are exactly similar to clearness. Interjections indicate sounds such as the special sound of a human or an animal and or colliding something to another thing.

There is no sound except pet pet of a wretched candle in vicinity of the death glum and close to morning and its hand is busy on the death (same: 157)

or he says in another place:

the thirsty fell in whisper (pech pech)

this is that same cloud having thousands of light (same: 54 )

\section{Resurrection of Dialectal Words}

In order to use a huge treasure of Persian words, Akhavan also applies words and dialectal words that are special for a region. He takes great care and delicacy and gives resurrection to these words. Examples of dialect words are:

and we throw our own boats into the endless, green and velvet-like sea such as almond kol (same: 160)

akhavan says in one of his interviews that ((kol e badam)) is a Yazdi dialect and I heard it from Yazdi people. Another sample of dialectal words, khosbideh (asleep), is given:

on the asleep ground (khosbideh), the picture of willow branches (same: 28)

\section{Semantic Resuurection}

The purpose of semantic resurrection in Akhavan's poem is artistic usage of types of simile, metaphor, irony-diagnosis, paradox, and creating sense that are stated in spiritual and novel frame. A poet or a writer do not disrupt usual system of word or sentence construction but states an issue by using usual words and imperative sentences which its context is against tradition and habit (Shiri, 2001: 13). Akhavan is also an innovative poet in applying spiritual techniques. He uses these literary arrays in such a way that gives his own speech meaning.

\subsection{Simile}

Simile remembers similarity that exists between two things from one or more aspects. It has been said that simile is news of likened thing and it is a sharing of two things in one or more adjectives and it has been said that simile is describing a thing to similar and close ones from one or more aspects (Shafiee Kadkani, 2009: 53).

Also, Akhavan such as Nima is of poet types who is modernist and tradition breaker in applying spiritual arrays. Similes used in Akhavan's poem are sometimes expressive and sometimes widespread that their element needs more mental attempts. Shamisa says: ((it is worth to think that strange similes against trite ones namely stereotypical and repetitive are resulted from poet's creative mind and show his/her novelty. Artists permanently increase world dimensions, fields, and meanings through this way and widen world (Shamisa, 1991: 108). Akhavan also has word resurrection in the field of simile. Pay attention to an example of simile in Winter poem:

\section{Rival! Host! Your yearly and monthly guest vibrates like wave at back of the door (same: 108)}

Akhavan similes the vibration of human body due to chill to the vibration of sea waves but he omits sea here and uses wave. The word ((wave)) remembers sea vibration and also vibration of human body. The word ((wave)) has been resurrected here.

\section{Metaphor}

Kazzazi says: ((one of the poetry techniques that using it a poet tries to place his/her own speech in the reader's mind 
more and more is the metaphor. The metaphor is tighter and more hidden than simile that a poet widens it against a reader or an audience)) (Kazzazi, 1994: 94). In contrary with simile that both sides are clear, in metaphor a reader should be able to discover hidden relations in the poet's words. More mental attempt for an audience to discover these relations, more literary pleasure will be provided. When Akhavan uses a meaning instead of another one, walk into a new field of speech, a speech that power of describing reality will be possible in it. Metaphor in Akhavan's poem is innovative, novel, and is accompanied by artistic creation, so that reader's mind achieves artistic meaning after an attempt and this meaning remains in mind. An example of metaphor in Akhavan's poem is as follows:

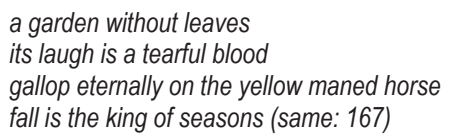

Yellow maned horse is a metaphor for yellow leaves of trees in autumn. Akhavan is innovative and well-known in constructing novel and new metaphors. Barahani says: ((tongue is forced to say something in a poem that never says them normally (Barahani, 1992: 55). We can see an example in Akhavan's poem.

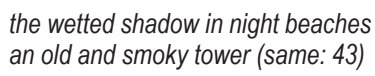

He similes night to a sea that walls of a tall tower smoked and shadowed due to night darkness are wetted in night sea. It means they have had a greater darkness. About this poem it can be said that the poet has used soaking instead of darkness and has caused its outstanding.

\section{Paradox}

Paradox means nonsensical and contradictory speech and also means an idea or statement that is in conflict with publicly acceptable ideas. Idiomatically, it is a language containing a contradicted concept apparently so that it seems meaningless at first glance, but behind its apparently absurd meaning, a fact is hidden. This apparent contradiction of sentence concept attracts attention of audience or reader and results in discovering its beautiful hidden concept (Mirsadeqi: paradox). Akhavan has applied paradox in an artistic form that attracts the audience mind to challenge with the issue and forces him/her to exploration. More pleasure has been earned for the audience due to this mind attempt. Thirsty sea is a paradox used by Akhavan in the following poem:

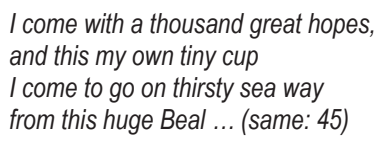

Logically, a sea cannot be thirsty, but it can help induction of mental concepts form view point of a poet. Here, story has been stated by a small pelican that calls everyone toward own-self and is a guide for the others who have been neglected and while they have blessing are excluded from them. Here, paradox has been applied to emphasize this issue.

\section{Making a Sense}

Making sense is the mixing two senses in the language in such a way it increases effectiveness of speech by creating spiritual music and causes its beauty. Making sense usually causes thinking about an issue. Akhavan has done this job very well and highlights his own favorite concepts.

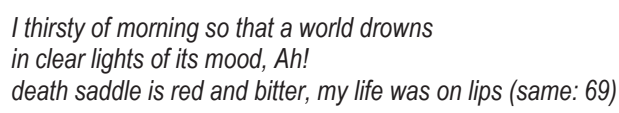

Akhavan mixes red color that is related to sense of sight with bitter that is related to sense of taste and emphasizes on the word (death). 


\title{
10.1 Music resurrection of the words
}

Akhavan also has necessary skill and art in the field of poem music. He repeats a word in every where necessary and doing this he causes resurrection of that word as well as creating music in the poem. Repetitive words are divided into two groups in Akhavan's poem: 1-noun 2-verb

\subsection{Noun}

Akhavan sometimes causes resurrection of a word by repeating a noun as well as emphasis on it.

Snow drink! Be flowered, burn

That this blood is our blood, the homeless

That this blood is hungry wolves'

That this blood is desert chlidrens' (same: 77)

He repeats it in another place for emphasis and resurrecting time:
Who was my enemy?
Only world's enemy
Both visible and hidden
A relentless soul
Time, time, time, time

\subsection{Verb}

In following poem, Akhavan repeats the verb (come see) twice and causes more emphasis on it and highlighting it as well as creating music.

\author{
Come see, come see \\ How I fight \\ How I make yellow the green blossoms
}

\section{Resurrectuion of Words Using Language Compounds}

Shafiee Kadkani says: ((constructing compound is one of the factors that brings the language out of addicted state from view point of Russian formalists. The reader is already familiarized with the components of one compound and from view point of Russian formalists he/she is addicted with those components, but this compound may be in a form that creates wonder and defamiliarization in readers and outcome of this familiarization is that we discover the fact of things) (Shafiee Kadkani, 2010: 28). Akhavan who is an innovative and creative poet in applying types of new literary arrays also has skill in this field. He sometimes constructs new compounds using words that he is familiarized with them and consequently makes defamiliarization. An example of these compounds in Akhavan's poem is as follows:

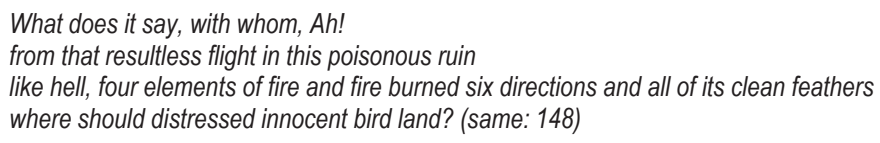

Here, Akhavan is previously familiarized with the words (ruin) and (poisonous), but this word usually is used with the other nouns. He constructs a new compound through putting these two words besides them that emphasizes on the word (ruin) as well as creating familiarization and resurrects them among hemistiches.

\section{Symbolism in Akhavan's Poem}

Various definitions have already been presented for symbolism. These definitions are so disturbed that do not convince any thinkers. Symbolism means a thing that shows another thing through comparison. The relation between them is paraphrastic. In other words, a symbol is a kind of language marker that points to its own evidence with a paraphrastic 
relation. Akhavan believes that poem should be targeted and promising. He says: ((I always have given some duties to the literature and they have always been some social and ethical ones... I consider a work as following ones that have social and human being effects. My works are evidence that my purpose have been social, revolutionary, and human being ones)) (Pourjafi, 2005: 245). The hope in using symbolism language is greatly under effect of Nima, but the difference between symbols in Nima's poem with Akhavan's poem is that Nima's symbols are difficult and hardunderstanding but Akhavan's symbols are intelligible with a little think. Akhavan has used symbols such as masticatoryWinter-barren in some his own poem in this collection. Some examples of symbols in Akhavan's poem:

\author{
My house has been fired, a heart-rending fire \\ This fire burns in every direction \\ Curtains and carpets with their warp and woof \\ I tearfully run in every direction \\ in fearsome and smoky fire.
}

Akhavan has used house as symbol of fatherland in this poem that has been burned by the fire of cruelty and burning warp and woof and curtains in that house are as symbol of destroying storages and properties of this land that were spoiled by foreigners. He resurrects them through applying them as symbol in his poem.

\title{
13. Conclusion
}

1. According performed investigations on words in Winter collection it can be said that Akhavan is of poets that his word range is extensive. He is an able poet in selecting words because he uses all of his mental ability to select the best word.

2. In selecting ancient words, contemporary Persian words, and dialectal and slang words, Akhavan artistically gathers them in a collection so that he has created friendship between them. He could greatly help treasure of Persian words in this field and revive contemporary Persian language again through Iranian original words.

3. By artistically selecting words, Akhavan revived them and caused resurrection of words in his poem. This resurrection of words can be a proper pattern for the other contemporary poets to use Iranian original words instead of using foreign words.

4. According to investigations performed in Winter collection, Akhavan has done most resurrection of words in the field of archaism. Applying these words is resulted from epic and national soul of the poet and his interest in Iranian nationality and culture. He could be as a connecting ring between old and today contemporary language and this is valuable for contemporary literature.

5. Akhavan never encounter with a lack of words as well as applying ancient and slang words besides contemporary Persian words and invents new words for induction of his mental concepts. The main material of these words is initial Persian language materials. Applying this type of innovation can be a suitable pattern for the other sciences.

\section{References}

Akhavan Sales, Mahdi (2011). Winter, Vol. (27), Tehran: Winter publication. Ilgelton, Teri (2001). Prologue on literary theories, translated by Abbas Mokhber, Second Edition. Tehran. Barahani, Reza (1991). Gold in copper. Vol. (1), first publication: Zaryab. Bahar, Mohammad Taghi (1991). Methodology, Vol. (1), sixth publish. Tehran: Amirkabir. Pournamdarian, Taghi (2002). Travel into fog. New edition. Tehran: Negah publication. Hoseinpour Jafi, Ali (2005). Flows of contemporary Persian poem. Tehran: Amirkabir publication. Hoghoughi, Mohammad (1996). The poet of the age 2. Vol. (3), Tehran: Negah publication. Dastgheib, ABdulali (1994). A look at Mahdi Akhavan Saleth. Vol. (1), Tehran: Morvarid. Rouyayee, Yadollah (2002). A dreamful message. Kalak No. (133). Shahin Dezhi, Shahriar (1999). The king of stone city. Tehran: Sokhan publication/ Shafiee Kadkani, Mohammadreza (2009). Imaginary forms in Persian poem. $13^{\text {th }}$ publication. Tehran: Agah publication. Shiri, Aliakbar (2001). The role of defamiliarization in creation of literary language. Persian literature and language training. №. (59). Safavi, Kourosh (2001). From linguistics to literature. Vol. (1), $2^{\text {nd }}$ publish, Tehran: Islamic culture and art researches. Tahbaz, Sirous (1995). A conversation with M. Omid. Time Notebook. No. 2. Kakhi, Morteza. (1992). Sound of wakeful wonder (Mahdi Akhavan Saleth's Conversations). 1st publish. Tehran: Winter. Kazzazi, Mirjalaleddin (1889). Aesthetics of Persian language. No. (34). 1st publish. Tehran: Markaz Publication. 
Mohammadi Amoli, Mohammadreza (1998). Chegour song. Tehran: Saleth Publication.

Meqdadi, Bahram (1999). Idiom culture of literary criticism from Plato up to now. Tehran: Fekr_e_Rouz Publication.

Mohaymeni, Saeed (2000). Poetry experience. Gilehva, Bamdad.

Mirsadeqi, Meimanat (1994). Poetry art dictionary. Tehran: Mahnaz Book. 